\title{
Características físico-químicas de derivados proteicos de soja em dietas extrusadas para cães
}

\author{
Physical-chemical characteristics of soy-protein derived in extruded diets for dogs
}

\author{
Ananda Portella Félix ${ }^{\mathrm{I}}$ Cleusa Bernardete Marcon de Brito ${ }^{\mathrm{II}}$ Hair Ferrarini ${ }^{\mathrm{II}}$ \\ Maria Inês Genovese Rodriguez ${ }^{\text {III }}$ Simone Gisele de Oliveira ${ }^{\text {IV }}$ Alex Maiorka ${ }^{\text {IV }}$
}

\section{RESUMO}

\begin{abstract}
A soja é um grão rico em proteínas e lipídeos, a partir do qual se obtém diversos derivados proteicos de alto valor nutricional. Em virtude disso, realizou-se este estudo com o objetivo de analisar a composição bromatológica de derivados proteicos de soja, bem como as características físicoquímicas dos extrusados formados a partir destes. Foram formuladas seis dietas para cães, uma referência e cinco contendo $30 \%$ de derivados de soja (farinha desengordurada - FDS, micronizada, farelo, grão integral e grão tostado), as quais foram extrusadas. Os derivados de soja e as dietas foram submetidos a análises bromatológicas e de qualidade do processamento. A FDS e o farelo de soja apresentaram os maiores teores de proteina bruta, enquanto os grãos de soja integral e tostado e a soja micronizada apresentaram os maiores teores de extrato etéreo em hidrólise ácida e energia bruta. A soja grão integral apresentou a maior atividade ureásica e inibitória de tripsina, mesmo após a extrusão da dieta. Os extrusados contendo as sojas grão e micronizada apresentaram as maiores densidades e as menores durezas, índice de absorção de água e grau de gelatinização do amido. Derivados proteicos de soja apresentam alto valor nutricional, entretanto, devem ser termicamente processados antes da extrusão para completa inativação do inibidor de tripsina. Além do mais, derivados contendo alto teor de lipídeos, como soja grão e micronizada, quando adicionados em $30 \%$ da fórmula, comprometem a qualidade do extrusado.
\end{abstract}

Palavras-chave: extrusão, farelo de soja, farinha desengordurada de soja, soja micronizada.

\section{ABSTRACT}

Soy is a grain rich in protein and lipids, from which its obtained different protein products of high nutritional value. This study aimed to analyze the chemical composition of different soy-protein products, as well as the characteristics of the extruded produced. Six diets were formulated, a reference and five with $30 \%$ soy product (defatted soy flour - DSF, micronized, soybean meal, crude grain or toasted grain), which were extruded. Soy products and diets were submitted to chemical analyses and process quality. The DSF and soybean meal presented the highest crude protein content, while the toasted and crude soybeans and micronized soy presented the highest acid hydrolyses ether extract and crude energy content. The crude soybean presented the highest ureatic activity and trypsin inhibitor activity, even after the diet extrusion. The soy beans and micronized soy extruded presented the highest density and the lowest hardness, water absorption index and starch gelatinization degree. Soy-protein products present high nutritional value, however they should be heated before extrusion to complete inhibition of trypsin inhibitor. Besides, soy products with high fat content, such as soybean and micronized soybean, when added to $30 \%$ reduced the extruded quality.

Key words: defatted soy flour, extrusion, micronized soy, soybean meal.

\section{INTRODUÇÃO}

O conhecimento do valor nutricional dos ingredientes é indispensável para a formulação de dietas balanceadas. Dentre os ingredientes proteicos vegetais utilizados na alimentação animal, destaca-se o farelo de soja, sendo o derivado de soja mais empregado

'Programa de Pós-graduação em Ciências Veterinárias, Universidade Federal do Paraná (UFPR), Rua dos Funcionários 1540, Cabral, 80035-050, Curitiba, PR, Brasil. E-mail: ananda_felix@yahoo.com.br. Autor para correspondência.

"Laboratório de Nutrição Animal, UFPR, Curitiba, PR, Brasil.

II'Departamento de Alimentos e Nutrição Experimental, Universidade de São Paulo (USP), São Paulo, SP, Brasil.

${ }^{\text {IV }}$ Departamento de Zootecnia, UFPR, Curitiba, PR, Brasil. 
em alimentos completos extrusados para cães, compondo entre 5 a $20 \%$ da fórmula. Entretanto, devido à alta demanda por farelo de soja, principalmente para alimentação de aves e suínos, a aquisição deste ingrediente está se tornando cada vez mais onerosa e difícil. Uma alternativa ao farelo de soja seria o grão de soja, que apresenta altos teores de proteínas $(35,0$ a 37,0\%) e lipídeos (17,0 a 18,0\%) (BELLAVER etal., 2002), tornando-o vantajosa fonte de proteínas e energia para as dietas.

No entanto, para o uso da soja na alimentação de monogástricos, é necessário que esta seja termicamente processada, com a finalidade de desativar os fatores antinutricionais presentes na soja integral, tais como lectinas e inibidores de tripsina e quimiotripsina, que prejudicam a digestão proteica (LIENER, 1994). Existem vários métodos de processamento térmico da soja para uso comercial, sendo o principal a tostagem. Entretanto, é importante que o processamento da soja seja bem controlado, já que o subaquecimento ou superaquecimento podem reduzir o aproveitamento de seus nutrientes pelos animais (MENDES et al., 2004). O subprocessamento da soja pode não desativar completamente os inibidores de proteases e o superaquecimento pode resultar em desnaturação proteica excessiva e formação de complexos entre a lisina e os carboidratos (reação de Maillard), reduzindo a disponibilidade de ambos (HEIDENREICH, 1994).

Desse modo, é possível que a extrusão de alimentos comerciais para cães já seja efetiva na inativação dos inibidores de proteases da soja, devido às altas temperaturas empregadas durante o processo $\left(110-180^{\circ} \mathrm{C}\right)$, como já demonstrado por PURUSHOTHAM et al. (2007), ao extrusar dietas para cães contendo $15 \%$ de inclusão de grão cru de soja. Entretanto, não foram encontrados estudos que avaliassem os efeitos de maiores níveis de inclusão do grão cru de soja sobre a desnaturação dos inibidores de proteases e a qualidade dos extrusados. Este fato é relevante, principalmente, ao se considerar que a extrusão de misturas com alto teor de lipídeos, em extrusora de rosca simples, pode prejudicar o processo e a qualidade dos extrusados formados (LIN et al., 1997). Em virtude do exposto, realizou-se este estudo com o objetivo de avaliar a composição nutricional e as características físicoquímicas de derivados proteicos de soja, bem como dos extrusados formados a partir destes.

\section{MATERIAL E MÉTODOS}

Foram analisados cinco derivados proteicos de soja: farinha desengordurada de soja (FDS), soja micronizada, farelo de soja, soja grão integral e soja grão tostado, bem como uma dieta referência (Tabela 1) e cinco dietas contendo $70 \%$ da fórmula referência e $30 \%$ de um dos derivados proteicos de soja supracitados.

Para produção do farelo e da farinha desengordurada, os grãos de soja passaram por rolos quebradores e foram separados da casca, a qual foi moída e tostada. A soja descascada passou pelo condicionador, pela laminação, extração de óleo, recuperação do solvente (hexano) e tostagem. Parte da casca foi incorporada à soja tostada, produzindo o farelo de soja com $42 \%$ de proteína bruta. Para produção da farinha desengordurada, a soja laminada tostada (sem inclusão de casca) foi moída em moinho de rolos. O grão de soja tostado foi obtido por meio do aquecimento com ar seco a $120-125^{\circ} \mathrm{C}$ dos grãos de soja íntegros em tostador de túnel. Para a produção da soja micronizada, os grãos de soja foram expostos à

Tabela 1 - Ingredientes e composição química analisada da dieta referência.

\begin{tabular}{|c|c|}
\hline \multicolumn{2}{|l|}{ Ingredientes (\%) } \\
\hline Milho & 59,08 \\
\hline Farinha de vísceras de frango & 26,14 \\
\hline Glúten de milho 60 & 5,71 \\
\hline Gordura industrial & 5,00 \\
\hline Hidrolizado de frango & 1,86 \\
\hline Propionato de cálcio & 0,17 \\
\hline Sorbato de potássio & 0,03 \\
\hline Suplemento mineral-vitamínico ${ }^{1}$ & 1,30 \\
\hline Sal comum & 0,71 \\
\hline Total & 100,00 \\
\hline ------------Composição química (\% na matéria seca)----- & $\begin{array}{r}\text { seca)----- } \\
90,97\end{array}$ \\
\hline Proteína bruta & 24,62 \\
\hline Extrato etéreo em hidrólise ácida & 11,01 \\
\hline Fibra bruta & 1,35 \\
\hline Fibra em detergente neutro & 8,55 \\
\hline Fibra em detergente ácido & 2,39 \\
\hline Matéria mineral & 7,00 \\
\hline Cálcio & 1,43 \\
\hline Fósforo total & 1,02 \\
\hline Extrativos não nitrogenados ${ }^{2}$ & 56,00 \\
\hline Energia metabolizável $\left(\mathrm{kcal} \mathrm{kg}^{-1}\right)^{3}$ & $4.020,25$ \\
\hline
\end{tabular}

${ }^{1}$ Enriquecimento kg de alimento $^{-1}$ : Vit. A - 20000UI; Vit. D 2000UI; Vit. E - 48mg; Vit. K - 48mg; Vit. B1 - 4mg; Vit. B2 $32 \mathrm{mg}$; Ácido Pantotênico - 16mg; Niacina - 56mg; Colina 800mg; Zinco - 150mg; Ferro - 100mg; Cobre - 15mg; Iodo 1,5mg; Manganês - 30mg; Selenio - 0,2mg e antioxidante $240 \mathrm{mg}$.

${ }^{2} \mathrm{ENN}(\%)=100-(\mathrm{MM} \%+\mathrm{PB} \%+\mathrm{EEA} \%+\mathrm{FB} \%)$, na matéria seca.

${ }^{3}$ Estimado segundo o NRC (2006). 
radiação infravermelha e ao vapor indireto à $165^{\circ} \mathrm{C}$, durante 2 à 3 minutos, seguido por retirada da casca, floculação e moagem por moinho de rolos.

A soja grão integral e grão tostado foi previamente moída em moinho de rolos a $2,5 \mathrm{~mm}$, para maior homogeneidade com os demais ingredientes na mistura. Os ingredientes foram misturados em misturador vertical e posteriormente moídos a $1 \mathrm{~mm}$ em moinho de martelos, extrusados em extrusora de rosca simples com capacidade de $4 \mathrm{t} \mathrm{h}^{-1}$ e secos em secador horizontal. Após secagem, as dietas extrusadas foram encaminhadas para recobrimento com gordura industrial e, após resfriamento, foram recobertas com hidrolisado de fígado de frango.

Os derivados proteicos de soja e a dieta referência foram moídos a $0,5 \mathrm{~mm}$ e analisados quanto à matéria seca (MS), proteína bruta (PB), extrato etéreo em hidrólise ácida (EEA), fibra bruta (FB), fibra detergente neutro (FDN), fibra detergente ácido (FDA), cálcio $(\mathrm{Ca})$, fósforo $(\mathrm{P})$ e matéria mineral $(\mathrm{MM})$, segundo a AOAC (1995) e energia bruta (EB), em bomba calorimétrica. Os extrativos não nitrogenados (ENN) foram estimados por: $100-$ (umidade $\%+\mathrm{PB} \%+\mathrm{EEA} \%$ $+\mathrm{FB} \%+\mathrm{MM} \%$ ).

Nos derivados proteicos de soja, rações fareladas e extrusadas, foram determinados a atividade inibitória de tripsina (GENOVESE \& LAJOLO, 1998), atividade ureásica e o índice de proteína dispersível (PDI), segundo a AOCS (1980a,b), e a proteína solúvel em KOH 0,2\% (ARABA \& DALE, 1990). Nas rações extrusadas, foram determinados o índice de absorção de água (IAA), segundo HOLAY \& HARPER (1982), grau de gelatinização do amido (CHIANG \& JOHNSON, 1977) e a densidade e dureza, em durômetro eletrônico. Todas as análises foram realizadas em triplicata e repetidas quando variaram mais de $5 \%$.
Foi realizada análise de correlação entre o teor de extrato etéreo em hidrólise ácida da ração e as características físicas do extrusado no pacote estatístico SAS (1996). Os dados foram apresentados por meio de estatística descritiva.

\section{RESULTADOS E DISCUSSÃO}

A composição química dos derivados proteicos de soja estão apresentados na tabela 2. A FDS e o farelo de soja apresentaram os maiores teores de PB, enquanto os grãos de soja integral e tostado e a soja micronizada apresentaram os maiores teores de EEA e EB. O farelo de soja e a soja grão tostado apresentaram valores inferiores de $\mathrm{PB}$ e FB e superiores de EEA e EB. Os níveis nutricionais dos derivados de soja avaliados foram próximos aos descritos por MENDES et al. (2004) e ROSTAGNO et al. (2005).

A soja grão integral apresentou a maior atividade ureásica e inibitória de tripsina, maior solubilidade da proteína em KOH e maior PDI (Tabela 3), uma vez que não foi submetida a processamento térmico. Os demais derivados apresentaram valores considerados dentro do ideal de urease (abaixo de 0,20 $\triangle \mathrm{pH}, \mathrm{BUTOLO}, 2002)$ e proteína solúvel em KOH (70$85 \%$, ARABA \& DALE, 1990) para sojas termicamente tratadas, com exceção da soja micronizada e da FDS, que apresentaram solubilidade proteica acima de $85 \%$.

Os valores encontrados no presente estudo para a soja crua corroboram os relatados por PURUSHOTHAM et al. (2007), os quais encontraram atividade ureásica de 2,0 $\Delta \mathrm{pH}$ e atividade inibitória de tripsina de 51UIT para o grão cru de soja. Em relação à solubilidade da proteína, LUSAS \& RIAZ (1995) relatam que sojas cruas apresentam PDI em torno de 40 a $90 \%$.

Tabela 2 - Composição química de derivados proteicos da soja na matéria natural.

\begin{tabular}{|c|c|c|c|c|c|}
\hline$(\%)$ & FDS & Micronizada & Farelo & Grão tostado & Grão integral \\
\hline MS & 93,9 & 95,7 & 89,2 & 89,7 & 90,0 \\
\hline $\mathrm{PB}$ & 49,2 & 39,0 & 41,7 & 33,7 & 33,8 \\
\hline EEHA & 2,4 & 20,6 & 3,7 & 21,0 & 20,8 \\
\hline MM & 5,7 & 4,5 & 5,4 & 4,4 & 4,4 \\
\hline FB & 1,5 & 1,4 & 4,7 & 3,7 & 3,6 \\
\hline FDN & 8,4 & 13,3 & 13,1 & 9,5 & 9,4 \\
\hline FDA & 3,3 & 4,1 & 6,7 & 8,4 & 8,2 \\
\hline ENN & 35,1 & 30,2 & 33,6 & 27,0 & 27,3 \\
\hline $\mathrm{Ca}$ & 0,4 & 0,2 & 0,4 & 0,3 & 0,3 \\
\hline $\mathrm{P}$ & 0,8 & 0,6 & 0,5 & 0,5 & 0,5 \\
\hline $\mathrm{EB}\left(\mathrm{kcal} \mathrm{kg}^{-1}\right)$ & 4383,5 & 5528,2 & 4209,7 & 5068,9 & 5103,8 \\
\hline
\end{tabular}

FDS: Farinha desengordurada de soja; MS: matéria seca; PB: proteína bruta; EEHA: extrato etéreo em hidrólise ácida; MM: matéria mineral; FB: fibra bruta; FDN: fibra em detergente neutro; FDA: fibra em detergente ácido; ENN: extrativos não nitrogenados; EB: energia bruta. 
Tabela 3 - Características físico-químicas de derivados proteicos de soja e das rações fareladas e extrusadas.

\begin{tabular}{|c|c|c|c|c|c|c|c|}
\hline \multirow{2}{*}{ Variáveis } & & REF & FDS & SM & FS & SGT & SGI \\
\hline & & \multicolumn{6}{|c|}{--------------------------------------'Ingredientes-------------------------------------- } \\
\hline Urease & $\Delta \mathrm{pH}$ & - & 0,22 & 0,04 & 0,05 & 0,07 & 1,74 \\
\hline Inibidor de tripsina & UIT & - & 9,0 & 6,6 & 6,6 & 3,1 & 45,1 \\
\hline Proteína solúvel & $\%$ & - & 87,4 & 89,6 & 82,2 & 82,4 & 97,9 \\
\hline \multirow[t]{2}{*}{ PDI } & $\%$ & - & 8,56 & 13,03 & 10,74 & 10,31 & 44,24 \\
\hline & & & \multicolumn{5}{|c|}{-----Rações fareladas contendo $30 \%$ do ingrediente-- } \\
\hline Urease & $\Delta \mathrm{pH}$ & 0,0 & 0,10 & 0,03 & 0,05 & 0,06 & 1,16 \\
\hline \multirow[t]{2}{*}{ Inibidor de tripsina } & UIT & 0,0 & 3,2 & 2,2 & 3,5 & 1,4 & 15,8 \\
\hline & & & \multicolumn{5}{|c|}{---Rações extrusadas contendo $30 \%$ do ingrediente- } \\
\hline Urease & $\Delta \mathrm{pH}$ & 0,00 & 0,04 & 0,00 & 0,03 & 0,01 & 0,03 \\
\hline Inibidor de tripsina & UIT & 0,00 & 1,7 & 2,2 & 2,0 & 1,5 & 4,1 \\
\hline IAA & $\%$ & 481 & 485 & 455 & 478 & 406 & 418 \\
\hline Densidade & $\mathrm{g} \mathrm{L}^{-1}$ & 449 & 433 & 498 & 467 & 518 & 491 \\
\hline Dureza & Kgf & 10,78 & 9,51 & 8,21 & 9,92 & 8,38 & 8,75 \\
\hline GGA & $\%$ & 90,0 & 90,0 & 68,0 & 90,0 & 68,0 & 66,0 \\
\hline
\end{tabular}

REF: ração referência; FDS: Farinha desengordurada de soja; SM: Soja micronizada; FS: Farelo de soja; SGT: Soja grão tostado; SGI: Soja grão integral. UIT: unidades inibitórias de tripsina. PDI: índice de proteína dispersível; IAA: Índice de absorção de água; GGA: Grau de gelatinização do amido.

Já a solubilidade da proteína da soja crua em $\mathrm{KOH}$ $0,2 \%$ é próxima de $100 \%$ (SILVEIRA\& SOUZA, 2007). A insolubilização da proteína durante o aquecimento da soja ocorre, principalmente, devido à polimerização proteica decorrida da reação de troca de pontes dissulfeto intermoleculares (CAPRITA \& CAPRITA, 2010).

Dentre as rações extrusadas, a ração contendo $30 \%$ de grão integral de soja apresentou maior atividade inibitória de tripsina, mas não a maior atividade ureásica. Isso indica que o processo de extrusão da ração contendo $30 \%$ de soja grão integral não é suficiente para completa inativação dos inibidores de proteases do grão. Além disso, apesar da determinação da urease ser um método mais prático e barato que a análise de inibidor de tripsina, não apresenta exatidão sobre a presença de inibidores de proteases, uma vez que os valores encontrados de urease nas rações extrusadas se mantiveram abaixo de $0,20 \Delta \mathrm{pH}$. Isso demonstra que a urease é uma enzima mais sensível à temperatura que o inibidor de tripsina, fato este também constatado por PURUSHOTHAM et al. (2007).

Hipotetiza-se que a incompleta inativação do inibidor de tripsina seja devido ao curto tempo de permanência da ração no canhão da extrusora (aproximadamente 30 a 60 segundos) e principalmente devido ao alto teor de óleo da mistura farelada contendo a soja grão integral, o que limita o aumento da pressão e temperatura no canhão da extrusora, devido ao efeito lubrificante do óleo.
De acordo com GENOVESE \& LAJOLO (1998), valores residuais de atividade inibitória de tripsina podem ser indicativos de inibição inespecífica, como interferência do fitato presente na soja, o qual pode complexar o cálcio do tampão utilizado no método. Segundo os autores, o cálcio é um cofator da tripsina e a sua complexação diminuiria a atividade desta, simulando a ação dos inibidores. Esse fato é uma possível justificativa para os valores de atividade inibitória de tripsina abaixo de 2,0UIT encontrados no presente estudo para as rações extrusadas contendo os derivados de soja desativados.

Apesar dos resultados obtidos no presente estudo, PURUSHOTHAM et al. (2007) relataram inativação eficiente $(<2,0$ UIT) do inibidor de tripsina ao extrusar uma fórmula de alimento completo para cães contendo $15 \%$ de soja crua entre $125-140^{\circ} \mathrm{C}$. Embora os autores não tenham apresentado o teor de extrato etéreo da fórmula extrusada, é provável que o menor nível de inclusão do grão de soja utilizado não tenha contribuído para o aumento excessivo do teor de lipídeos da mistura, como no presente estudo, não comprometendo a pressão e temperatura no interior do canhão.

O efeito adverso de altos teores de lipídeos sobre o processo de extrusão em rosca simples também pode ter influenciado sobre as características físicas avaliadas nos extrusados (Tabela 3), as quais apresentaram alta correlação com o teor de lipídeos da ração (Tabela 4). Os extrusados contendo as sojas grão e micronizada apresentaram as maiores densidades, as 
Tabela 4 - Correlação entre o teor de extrato etéreo em hidrólise ácida da ração e as características físicas do extrusado.

\begin{tabular}{lllll}
\hline & GGA & IAA & Dureza & Densidade \\
\hline EEA & $-0,97$ & $-0,92$ & $-0,84$ & 0,93 \\
$\mathrm{P}$ & $<0,001$ & $<0,001$ & $<0,001$ & $<0,001$ \\
\hline
\end{tabular}

IAA: Índice de absorção de água; GGA: Grau de gelatinização do amido.

menores durezas, os menores IAA e os menores graus de gelatinização do amido. Isso indica que o elevado teor de lipídeos desses derivados pode ter prejudicado a gelatinização do amido e, por conseguinte, resultado em extrusados menos expandidos e de menor durabilidade. O teor de extrato etéreo em hidrólise ácida das misturas fareladas contendo $30 \%$ de soja grão tostado foi de $10,8 \%$; soja grão integral: $10,9 \%$; soja micronizada: $9,9 \%$; farelo de soja: $6,7 \%$ e FDS: $5,2 \%$. Desse modo, é provável que teores de EEHA acima de $6,7 \%$ da mistura farelada comprometam o processo de extrusão em rosca simples.

Resultados semelhantes foram descritos por LIN et al. (1997), os quais, avaliando a adição de lipídeos sobre o processo de extrusão, observaram redução de 100 a 55\% no grau de gelatinização do amido em rações extrusadas contendo 0 a $7,5 \%$ de extrato etéreo, respectivamente. Segundo os autores, a adição de lipídeos durante a extrusão pode comprometer a gelatinização do amido, devido ao efeito lubrificante do óleo, diminuindo a pressão de cisalhamento no canhão da extrusora e dificultando a absorção de água pelos grânulos de amido.

Derivados proteicos de soja apresentam bom perfil nutricional para serem utilizados em alimentos para cães como fonte proteica (farelo, farinha desengordurada, soja micronizada e grão tostado) e energética (grão de soja tostado e soja micronizada), ponderando as necessidades nutricionais de proteínas e lipídeos reportadas pelo NRC (2006) para esses animais. Além disso, uma vez associadas às farinhas de origem animal, permitem fornecimento dos níveis proteicos desejados, ao mesmo tempo em que moderam os níveis de macrominerais (principalmente cálcio) nas formulações, pois possuem alta relação de proteína bruta: matéria mineral, ao contrário dos coprodutos de origem animal. Entretanto, os derivados proteicos de soja com alto teor de lipídeos, inclusos em $30 \%$ na formulação, devem ser termicamente tratados antes da extrusão em rosca simples, para completa inativação do inibidor de tripsina.

Cabe ressaltar ainda que a determinação da urease, por ser uma enzima inativada em temperaturas menores que o inibidor de tripsina (PURUSHOTHAM et al., 2007) e se tratar de um método não linear, deve ser utilizada com cautela na prática, para se evitar o uso de alimentos com inibidores de proteases ativos na nutrição animal. A não linearidade desse método pode ser observada, por exemplo, na redução não proporcional da variação de $\mathrm{pH}$ entre os ingredientes e as rações fareladas contendo $30 \%$ do derivado de soja (redução de $0 \%$ a 54\%, em relação à atividade medida no ingrediente). Em contrapartida, a atividade inibitória de tripsina foi reduzida com maior proporcionalidade frente à diluição de $70 \%$ do fator antitríptico nas rações fareladas contendo $30 \%$ dos derivados de soja (redução de 67\% a 55\%, em relação à atividade medida no ingrediente).

\section{CONCLUSÃO}

Derivados proteicos de soja apresentam alto teor proteico, podendo ser, também, fontes energéticas quando não desengordurados. $O$ processo de extrusão em rosca simples não é suficiente para completa inativação do inibidor de tripsina em formulação contendo $30 \%$ de grão cru de soja. A análise da atividade ureásica apresenta menor sensibilidade que a determinação da atividade inibitória de tripsina, para determinação da presença de inibidores de proteases em derivados de soja e rações extrusadas. A soja grão e a micronizada, quando adicionadas em $30 \%$ da fórmula, comprometem a qualidade do extrusado.

\section{REFERÊNCIAS}

AOCS (American Oil Chemists Society). Urease activity. Official method Ba 9-58. Champaign, IL, 1980a. 77p.

AOCS (American Oil Chemists Society). Protein dispersibility index. Official method Ba 10-65. Champaign, IL, 1980b. 77p.

AOAC (Association of the Official Analytical Chemists). Official and tentative methods of analysis. 16.ed. Arlington, 1995. 2000p

ARABA, M.; DALE, N.M. Evaluation of KOH solubility as an indicator of overprocessing soybean meal. Poultry Science, v.69, p.76-83, 1990.

BELLAVER, C. et al. Soja integral: processamento e uso. Alimentação Animal, v.7, p.28-30, 2002.

BUTOLO, J.E. Qualidade de ingredientes na alimentação animal. Campinas: CBNA, 2002. 430p.

CAPRITA, A.; CAPRITA, R. Modification of the soluble protein content of heat-processed soybean flour. Notulae Botanicae Horti AgrobotaniciCluj-Napoca, v.38, n.2, p.98-101, 2010. Disponível em: <http://notulaebotanicae.ro/nbha/article/ viewFile/4747/4518>. Acesso em: 02 ago. 2010.

Ciência Rural, v.40, n.12, dez, 2010. 
CHIANG, B.Y.; JOHNSON, J.A. Measurement of total and gelatinized starch by glucoamylase and o-toluidine reagent. Cereal Chemistry, v.54, p.429-435, 1977.

GENOVESE, M.I.; LAJOLO, F.M. Atividade inibitória de tripsina em produtos derivados de soja (Glycine max) consumidos no Brasil. Ciência e Tecnologia de Alimentos, v.18, n.3, p.309-312, 1998. Disponível em: <http:// www.scielo.br/scielo.php?script $=$ sci arttext\&pid $=\mathrm{S} 0101$ 20611998000300010>. Acesso em: 22 maio, 2008. doi: 10.1590/S0101-20611998000300010.

HEIDENREICH, E. Operation strategies for expansion cooking. Feed Mix, v.2, p.32-34, 1994.

HOLAY, S.H., HARPER, J.M. Influence of extrusion shear environment on plant texturization. Journal of Food Science, v.47, n.6, p.1869-1874, 1982.

LIENER, I.E. Implication of antinutritional components in soybean foods. Critical Review of Food Science Nutrition, v.34, p.31-67, 1994. Disponível em: http://www.ncbi.nlm.nih.gov/ pubmed/8142044. Acesso em: 11 jun. 2009.

LIN, S. et al. Effects of lipids and processing conditions on degree of starch gelatinization of extruded dry pet food. Lebens Wiss Technology, v.30, p.754-761, 1997.

LUSAS, E.W.; RIAZ, M.N. Soy protein products: processing and use. Journal of Nutrition, v.125, p.573S-580S, 1995.
Disponível em: <http://jn.nutrition.org/cgi/content/abstract/ 125/3_Suppl/573S >. Acesso em: 12 maio, 2008.

MENDES, W.S. et al. Composição química e valor nutritivo da soja crua e submetida a diferentes processamentos térmicos para suínos em crescimento. Arquivo Brasileiro de Medicina Veterinária e Zootecnia, v.56, p.207-213, 2004. Disponível em: <http://www.scielo.br/pdf/abmvz/v56n2/20331.pdf>. Acesso em: 11 jun. 2009.

NRC (Nacional Research Council). Nutrient requirements of dogs and cats. Washington, DC: National Academy, 2006. $426 \mathrm{p}$.

PURUSHOTHAM, B. et al. Effects of steam conditioning and extrusion temperature on some anti-nutritional factors of soyabean (Glycine max) for pet food applications. American Journal of Animal and Veterinary Sciences, v.2, n.1, p.15, 2007. Disponível em: <http://www.scipub.org/fulltext/AJAV/ AJAV211-5.pdf>. Acesso em: 11 jun. 2009.

ROSTAGNO, H.S. et al. Tabelas brasileiras para aves e suínos (composição de alimentos e exigências nutricionais). Viçosa, MG: UFV, 2005. 186p.

SAS. Statistical Analysis System: users guide. Cary, NC, 1996. 584p.

SILVEIRA, C.O.; SOUZA, C.F.V. Variações do método de quantificação da proteína solúvel em soja desativada utilizada na alimentação animal. Revista Brasileira de Tecnologia Agroindustrial, v.1, n.2, p.117-127, 2007. 